\title{
The interaction of modified histones with the bromodomain testis-specific (BRDT) gene and its mRNA level in sperm of fertile donors and subfertile men
}

\author{
Cornelia Steilmann ${ }^{1}$, Márcia C O Cavalcanti ${ }^{1}$, Marek Bartkuhn², Jörn Pons-Kühnemann ${ }^{3}$, \\ Hans-Christian Schuppe ${ }^{1}$, Wolfgang Weidner ${ }^{1}$, Klaus Steger $^{1}$ and Agnieszka Paradowska ${ }^{1}$ \\ ${ }^{1}$ Department of Urology, Pediatric Urology and Andrology, Rudolf Buchheim-Strasse 7, Justus Liebig University, \\ 35385 Giessen, Germany and ${ }^{2}$ Institute for Genetics and ${ }^{3}$ Institute for Medical Informatics, Justus Liebig University, \\ 35392 Giessen, Germany
}

Correspondence should be addressed to C Steilmann; Email: cornelia.steilmann@chiru.med.uni-giessen.de

\begin{abstract}
As histone modifications have been suggested to be involved in the regulation of gene expression after fertilisation, the present study aimed to analyze the interaction between the bromodomain testis-specific (BRDT) gene and differentially modified histones in human spermatozoa. The BRDT transcript level was studied to identify possible correlations between epigenetic changes, mRNA level and subfertility associated with impaired sperm chromatin condensation. Chromatin immunoprecipitation (ChIP) was performed with ejaculates from fertile and subfertile men using antibodies against specifically acetylated and methylated histone $\mathrm{H} 3$.

Immunoprecipitated DNA was analysed by real-time quantitative PCR with primer pairs for BRDT. The BRDT mRNA level was screened by real-time RT-PCR. ChIP assay revealed co-localisation of acetylated and methylated histones within promoter and exon regions of the $B R D T$ gene in fertile men. Interestingly, reduced binding of investigated modified histone modifications was observed in the $B R D T$ promoter of subfertile patients. Different mRNA levels of $B R D T$ have been detected in a group of infertile patients, as well as in fertile men. Enrichment of methylated histones within the BRDT promoter of fertile sperm suggests that this epigenetic mark may cause repression of $B R D T$ after fertilisation, and may be changed in infertile patients. Our data suggest that reduced histone methylation in the promoter of $B R D T$ may be associated with increased transcript levels in subfertile patients.

Reproduction (2010) $\mathbf{1 4 0} 435-443$
\end{abstract}

\section{Introduction}

During human spermiogenesis, $\sim 85 \%$ of histones are replaced by protamines (Tanphaichitr et al. 1978, Gatewood et al. 1987, Steger et al. 1998), while the remaining histones exhibit acetylated and methylated lysine residues within their $\mathrm{N}$-terminal tails (Allfrey et al. 1964). It has been proposed that modified histones are involved in the regulation of gene expression after fertilisation (Bernstein et al. 2007). Genes associated with modified histones, therefore, might be essential for early embryo development, as it has been demonstrated that genome regions expressed during early embryogenesis are histone-enriched (Gardiner-Garden et al. 1998, Wykes \& Krawetz 2003, Rousseaux et al. 2008). In addition, Hammoud et al. (2009) reported that nucleosomes and especially histone modifications are enriched at genomic regions of developmental importance, such as imprinted gene clusters, microRNA clusters, $H O X$ gene clusters and promoters of stand-alone developmental transcription and signalling factors. Arpanahi et al. (2009) demonstrated that acetylated histone 4 at lysine $12(\mathrm{H} 4 \mathrm{~K} 12 \mathrm{ac})$ is associated with gene regulatory regions, including promoter regions and sequences recognised by the CCCTC-binding factor.

In addition to epigenetic marks transmitted by modified histones from the spermatozoon to the oocyte, certain mRNAs are synthesised prior to transcriptional arrest during spermatogenesis and then stored in mature spermatozoa which have been postulated to make a paternal contribution to gene expression in the early embryo (Ostermeier et al. 2004, Lalancette et al. 2008). Although most of the spermatozoal transcripts disappear at the four-cell stage of embryo differentiation, studies derived from mouse implantation embryos confirmed that some RNAs are translated after fertilisation. For example, paternal PLC $\zeta$ ( $P L C Z 1$ ) RNA has been suggested to activate the oocyte through calcium oscillation after fertilisation (Swann et al. 2006). Another transcript, Kit, may epigenetically alter the phenotype of murine offspring (Rassoulzadegan et al. 2006).

The BRDT gene and its transcripts (bromodomain testis-specific gene, also referred to as FSRG3 or BRD6) 
represent potential candidates for studying the role of epigenetic changes for fertility and paternal contribution to the embryo, as they play an important role in the establishment of proper germ cell differentiation (Jones et al. 1997, Pivot-Pajot et al. 2003, Shang et al. 2004). The first bromodomain of the BRDT protein recognises the acetylation marks of histone 4 in order to start chromatin remodelling (Morinière et al. 2009). In addition, male mice carrying a mutation within the allele of the first bromodomain are subfertile (Shang et al. 2007). BRDT transcripts have been demonstrated to be specifically expressed in human and murine testis. In the latter, Brdt mRNA has been observed from pachytene spermatocytes to spermatids (Haynes et al. 1992, Zheng et al. 2005, Shang et al. 2007). In man, a splicing variant of the BRDT gene (BRDT-NY) was found in embryonic and adult human testis and spermatozoa from fertile men (Zheng et al. 2005). By contrast, transcripts of this splicing variant could not be detected in testis of some azoospermic men including arrest of spermatogenesis at the level of round spermatids (Zheng et al. 2005). As spermatozoa are known to contain a variety of transcripts (Zao et al. 2006) and mRNAs could be delivered from sperm to oocyte (Ostermeier et al. 2002), it might be possible that BRDT mRNA influences chromatin compaction during spermiogenesis and/or expression of BRDT during early embryogenesis (Miller et al. 2005, Zheng et al. 2005).

The aim of the present study was to analyse whether, in human spermatozoa, the BRDT gene is associated with modified histones. Based on our preliminary experiments testing specificity of several antibodies against modified histones $\mathrm{H} 3$ and $\mathrm{H} 4$ by immunochemistry (Hecht et al. 2009) and chromatin immunoprecipitation (ChIP) assay, we selected following histone modification for our study with fertile and subfertile patients: histone $\mathrm{H} 3$ acetylated at lysine 9 (H3K9ac), histone $\mathrm{H} 3$ dimethylated at lysine $9(\mathrm{H} 3 \mathrm{~K} 9 \mathrm{dm})$, histone $\mathrm{H} 3$ trimethylated at lysine $9(\mathrm{H} 3 \mathrm{~K} 9 \mathrm{tm})$ and histone $\mathrm{H} 3$ trimethylated at lysine $27(\mathrm{H} 3 \mathrm{~K} 27 \mathrm{tm})$.

Binding loci for histones in the BRDT gene were investigated as shown in Fig. 1. In addition, we analysed whether there are differences in BRDT-histone interactions between fertile and infertile men. Our recent results obtained from ChIP using antibodies

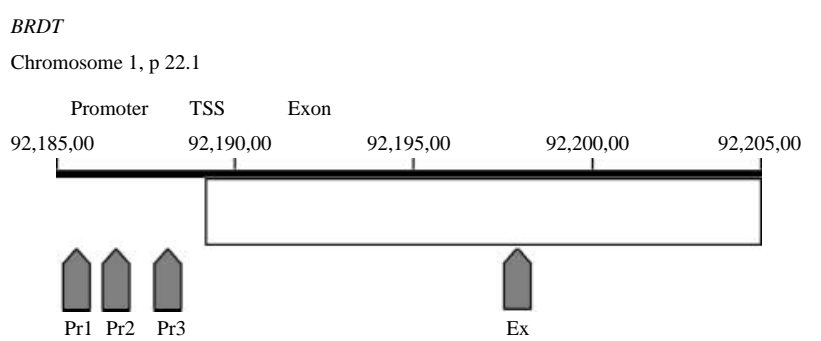

Figure 1 Part of the genomic region of the BRDT gene (chromosome 1, p 22.1). Primer pairs are located within the promoter $(\operatorname{Pr} 1-3)$ and the first exon (Ex). TSS, transcription start site. against H4K12ac in combination with a promoter array (ChIP-on-chip) provided additional information on the binding of H4K12ac to the promoter region of BRDT in fertile (Arpanahi et al. 2009) and infertile patients (data not published). Finally, we analysed the BRDT mRNA level in sperm of both fertile and subfertile men, as the population of RNA in mature ejaculated spermatozoa may reflect transcriptional activity during normal or impaired spermatogenesis.

\section{Results}

ChIP in combination with real-time quantitative PCR (qPCR) indicated an enrichment of H3K9ac, H3K9dm, $\mathrm{H} 3 \mathrm{~K} 9 \mathrm{tm}$ and $\mathrm{H} 3 \mathrm{~K} 27 \mathrm{tm}$ associated with the promoter region and exon of the $B R D T$ gene in fertile men. We used unmodified histone $\mathrm{H} 3$ as positive control, as it is present in all nucleosomes. H3 exhibited the lowest enrichment in promoter region $1(10 \%)$ and the highest enrichment in the exon (35\%). Non-specific IgG served as a negative control, which showed low enrichment values of non-specific binding to the genomic regions of the BRDT gene (Fig. 2).

In spermatozoa from fertile men, $\mathrm{H} 3 \mathrm{~K} 9 \mathrm{ac}$ exhibited a relative enrichment to the input in all regions of the $B R D T$ gene. The highest enrichment was found in promoter region $2(9 \%)$ and the lowest enrichment in promoter region 1 (2\%; Fig. 2). Furthermore, histones $\mathrm{H} 3 \mathrm{~K} 9 \mathrm{dm}, \mathrm{H} 3 \mathrm{~K} 9 \mathrm{tm}$ and $\mathrm{H} 3 \mathrm{~K} 27 \mathrm{tm}$ showed enrichment at the $B R D T$-binding site $(2-21 \%)$ with the lowest values in the exon (Fig. 2).

In spermatozoa of subfertile patients, ChIP in combination with qPCR was performed using two different pooled groups of patients $(n=5$ and $n=6)$. The negative control IgG revealed nearly no enrichment $(0.04-0.6 \%)$. The non-specific binding was lower than in fertile men (Fig. 2). The positive control $\mathrm{H} 3$ revealed an enrichment which was by trend higher than in fertile men $(9-98 \%$; Fig. 2). Interestingly, enrichment values of acetylated $\mathrm{H} 3 \mathrm{~K} 9$ were lower in the promoter regions $(1-4 \%)$, but four times higher in the exon when compared with fertile men (Fig. 2). Methylated histones exhibited a lower enrichment than in fertile men $(0-5 \%)$, except for $\mathrm{H} 3 \mathrm{~K} 27 \mathrm{tm}$ (3-24\%; Fig. 2). Within the exon, H3K27tm displayed enrichment 12 times higher than in fertile men.

Regarding the S.D., all values were lower in infertile patients than in fertile men, except for $\operatorname{lgG}$ at promoter 1 and exon region, $\mathrm{H} 3$ at promoter $3, \mathrm{H} 3 \mathrm{~K} 9 \mathrm{dm}$ at promoter 1 and $\mathrm{H} 3 \mathrm{~K} 27 \mathrm{tm}$ at the exon.

Data obtained from ChIP-on-chip promoter microarray revealed that histone $\mathrm{H} 4$ acetylated at lysine 12 (H4K12ac) was not associated with the BRDT promoter, neither in sperm from fertile men, nor from subfertile patients (Fig. 3A and B). Using material from three fertile donors, the validation of microarray data confirmed no binding sites. However, interaction with another member of the BRD family, namely BRD9, was identified 

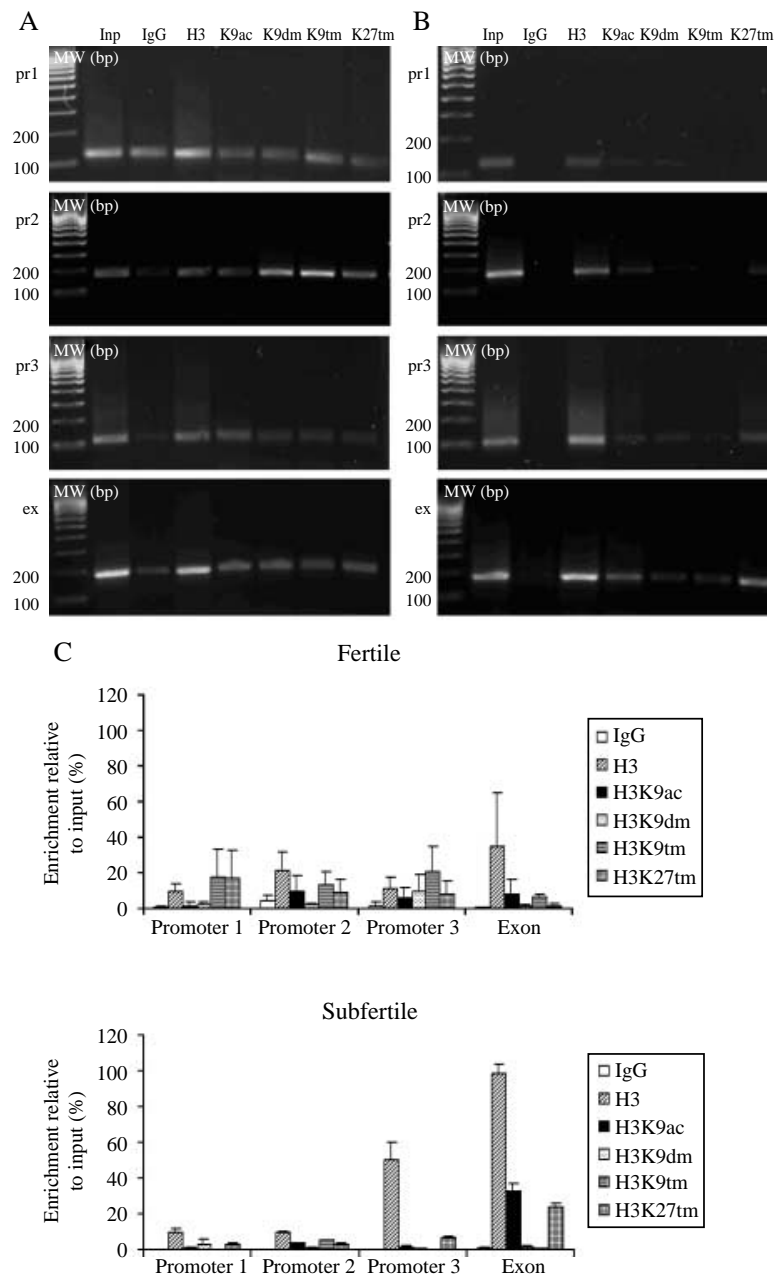

Figure 2 Results from ChIP in combination with real-time PCR. Immunoprecipitated DNA of fertile (A) and subfertile men (B) and different modified histones (H3K9ac, H3K9dm, H3K9tm and $\mathrm{H} 3 \mathrm{~K} 27 \mathrm{tm}$ ) were used. $\mathrm{H} 3$ served as positive control, and IgG served as negative control. Three different primer pairs were applied to analyse binding sites within the promoter region, while one primer pair was specific for a binding site within the first exon. Lane 1 on each gel represents a 1000-bp marker (Bio-Rad). (C) Enrichment pattern of $\mathrm{H} 3 \mathrm{~K} 9 \mathrm{ac}, \mathrm{H} 3 \mathrm{~K} 9 \mathrm{dm}, \mathrm{H} 3 \mathrm{~K} 9 \mathrm{tm}$ and $\mathrm{H} 3 \mathrm{~K} 27 \mathrm{tm}$ in the promoter region (1-3) and the first exon of the BRDT gene in a group of fertile and subfertile men. Range of S.D.s of modified histones in different gene regions: fertile men: IgG: 0.3-3.3, H3: 4.1-30.6, H3K9ac: 1.9-9.4, H3K9dm: 1.0-9.5, H3K9tm: 1.5-15.4, H3K27tm: 1.2-15.1; subfertile men: IgG: 0.0-0.4, H3: 1.3-9.1; H3K9ac: 0.0-4.8, H3K9dm: 0.3-2.9, H3K9tm: 0.1-0.4, H3K27tm: 0.6-2.1.

by binding peaks in DNA of fertile donors (false discovery rate score, $\mathrm{FDR}=0.140 ;$ Fig. $3 \mathrm{C}$ ). In subfertile patients, the peak corresponds to the BRD9-binding site with $\mathrm{FDR}=0.367$ (Fig. 3D). We did not detect a binding position for H4K12ac in the promoter, suggesting that this histone modification represents no potential interaction partner with the testis-specific BRDT gene. $B R D T$ mRNA was identified in sperm from fertile and subfertile men (Fig. 4A), and a difference was found between both groups ( $t$-test: $P=0.017)$. A range of one- to six-fold changes was observed in ejaculates of fertile men. By contrast, in ejaculates of subfertile patients, there was a range of 1 - to 11 -fold changes. Means of the fold changes from fertile versus subfertile men were calculated, as shown in Fig. 4B.

Statistical analysis based on a calculation of correlation coefficients between BRDT mRNA level and diagnostic parameters revealed no significant correlation with any of the investigated variables (Fig. 5). There was no significant relation of BRDT mRNA level to pregnancy. However, a tentative relationship could be observed when BRDT mRNA level was correlated with sperm morphology (Spearman correlation coefficient $r=-0.261, P=0.073)$ and aniline blue staining $(2+3$; $\%, r=0.260, P=0.084)$. In addition, patients exhibiting aniline blue staining of spermatozoa lower than $25 \%$ $(2+3)$ also displayed a lower BRDT mRNA level $(<25 \%$ aniline blue $(2+3)$ - mean BRDT mRNA level $=5.77$ \pm 2.49 vs $>25 \%$ aniline blue $(2+3)-$ mean BRDT mRNA level 7.11 \pm 2.0 ). As normal sperm morphology and efficient chromatin condensation are required for successful fertilisation, the correspondence between $B R D T$ mRNA level with sperm morphology and chromatin condensation is not surprising.

\section{Discussion}

In the present study, we analysed the interaction of histones $\mathrm{H} 3 \mathrm{~K} 9 \mathrm{ac}, \mathrm{H} 3 \mathrm{~K} 9 \mathrm{dm}, \mathrm{H} 3 \mathrm{~K} 9 \mathrm{tm}$ and $\mathrm{H} 3 \mathrm{~K} 27 \mathrm{tm}$ with the $B R D T$ gene, as well as the BRDT mRNA level, in sperm of fertile and subfertile men. ChIP analysis provided evidence that the promoter region of the $B R D T$ gene may interact with more than one histone modification. These findings are in agreement with data from Bernstein et al. (2005, 2006, 2007) and Azuara et al. (2006), who described overlapping regions of two different modified histones as 'bivalent domains'. In addition, identical binding patterns of several modified histones have been reported by Wang et al. (2008). The combinatorial patterns of modified histones at these domains might, therefore, conserve the epigenetic information for chromatin remodelling (Wade et al. 1997, Strahl \& Allis 2000, Turner 2000, Schreiber \& Bernstein 2002). However, when pluripotent cells start to differentiate, only one of two marks is preserved (Bernstein et al. 2005, Azuara et al. 2006) being involved in either expression or repression of a gene.

Concerning enrichment of $\mathrm{H} 3 \mathrm{~K} 9 \mathrm{ac}, \mathrm{H} 3 \mathrm{~K} 9 \mathrm{dm}$, $\mathrm{H} 3 \mathrm{~K} 9 \mathrm{tm}$ and $\mathrm{H} 3 \mathrm{~K} 27 \mathrm{tm}$ at the BRDT gene in spermatozoa, we observed only small differences between fertile and subfertile men. In subfertile men, only a few values were not within the range of the S.D. of fertile men. The association of methylated histones with BRDT suggests its transcriptional repression during late spermatogenesis, as the association and repressive function of the three states of $\mathrm{H} 3 \mathrm{~K} 9$ methylation (in combination with $\mathrm{H} 3 \mathrm{~K} 9 \mathrm{ac}$ ) were described for the 

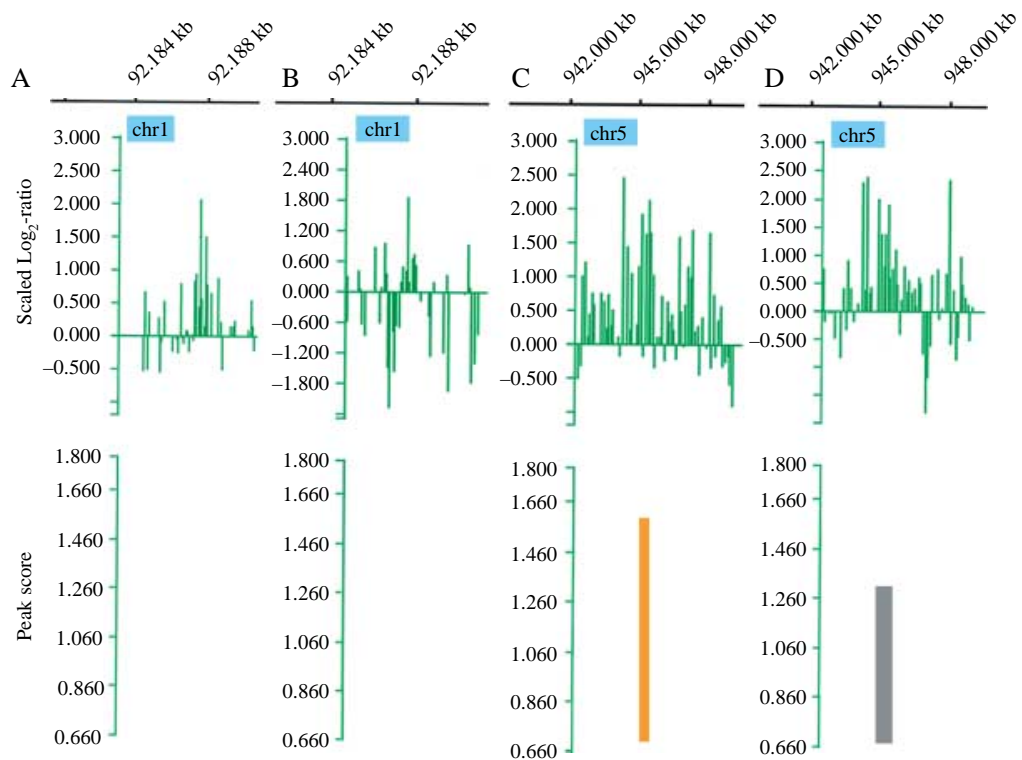

$\left.\begin{array}{l}1.800 \\ 1.660- \\ 1.460 \\ 1.260 \\ 1.060 \\ 0.860 \\ 0.660\end{array}\right]$

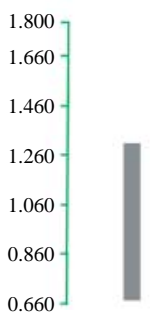

Figure 3 ChIP-on-chip analysis with H4K12ac peak visualisation within BRDT and BRD9 promoters by SignalMap Genome Browser (NimbleGen). $\log _{2}$ ratios were calculated from the input signals for the experimental ( $10 \%$ genomic DNA) and test samples (H4K12ac) that were co-hybridised to the array. No significant peaks within BRDT promoters on chromosome 1 could be identified in fertile (A) and subfertile (B) men. The BRD9 peak with FDR score $=0.140$ (orange bar) indicated high confidence binding of H4K12ac in fertile men (C). In subfertile patients (D), low probability of the peak in BRD9 was observed, as indicated by grey bar. FDR $=0.367$. The lower the FDR score, the more likely the peak corresponds to a histone-binding site on the DNA. stromal membrane-associated GTPase-activating protein (SMAP) gene in human $\mathrm{CD} 4{ }^{+} \mathrm{T}$ cells (Wang et al. 2008).

In general, it has been reported that lysine acetylation correlates with transcriptional activity, while methylation can have both effects: transcriptional activation (H3K4, H3K36; Santos-Rosa et al. 2002), or repression (H3K9, H3K27 and H4K20; Bernstein et al. 2007, Li et al. 2007). However, the function of modified histones in transcriptional regulation is not fully clarified. Furthermore, it has been proposed that every modification has the potential to activate or repress by different conditions. In our study, dimethylated $\mathrm{H} 3 \mathrm{~K} 9$ could have a repressive function in the promoter and an activating function in the exon, as Vakoc et al. (2005) proposed for this modification in mammalian chromatin.

Using microarray analysis, Dobson et al. (2004) detected BRDT mRNA expression in primary and secondary oocytes, and that a two- to three-fold downregulation of $B R D T$ on days 1-2 post-fertilisation suggests a paternal contribution to the regulation of $B R D T$ expression in the embryo. These data support our hypothesis that an increase in histone methylation in the promoter of spermatozoal DNA may arrest the expression of $B R D T$ until day 3 after fertilisation which is then followed by rearrangement of paternal epigenetic marks with maternal histones.

According to ChIP-seq results (Hammoud et al. 2009), the $B R D T$ promoter was found to be occupied by H3K4me3. Furthermore, authors showed that trimethylated $\mathrm{H} 3 \mathrm{~K} 27(\mathrm{H} 3 \mathrm{~K} 27 \mathrm{tm})$ is significantly enriched at developmental promoters that are repressed in early embryos, including many bivalent $(\mathrm{H} 3 \mathrm{~K} 4 \mathrm{tm} / \mathrm{H} 3 \mathrm{~K} 27 \mathrm{tm})$ promoters. Concerning BRDT, we could identify high enrichment of $\mathrm{H} 3 \mathrm{~K} 27 \mathrm{tm}$ to promoter 1 and promoter 2 regions in fertile donors (Fig. 2) giving rise to the idea of bivalent promoter occupancy in BRDT gene. In contrast,
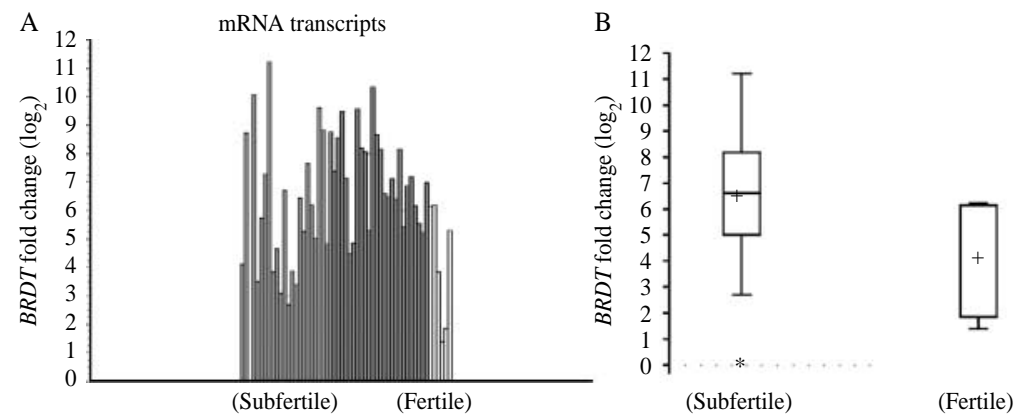

Figure 4 Analysis of $B R D T$ transcripts. (A) BRDT mRNA transcripts in spermatozoa of fertile ( $n=6$, white bars) and subfertile ( $n=49$, grey bars) men. The lowest expression value was reset to 0 as reference; therefore, for subfertile men, only 48 grey bars are shown instead of 49 . The range of one- to six-fold changes was observed in ejaculates of fertile men, while higher individual variation of 1 - to 11 -fold changes has been recognised in the group of subfertile patients. (B) Distribution of $B R D T$ fold change by group of fertile versus subfertile patients. The $B R D T$ level was significantly higher in the group of subfertile men (mean $6.53 \pm$ s.D. 2.27 ) when compared with the group of healthy controls (mean $4.12 \pm$ s.D. $2.12 ; P_{t \text {-test }}=0.017$ ). 

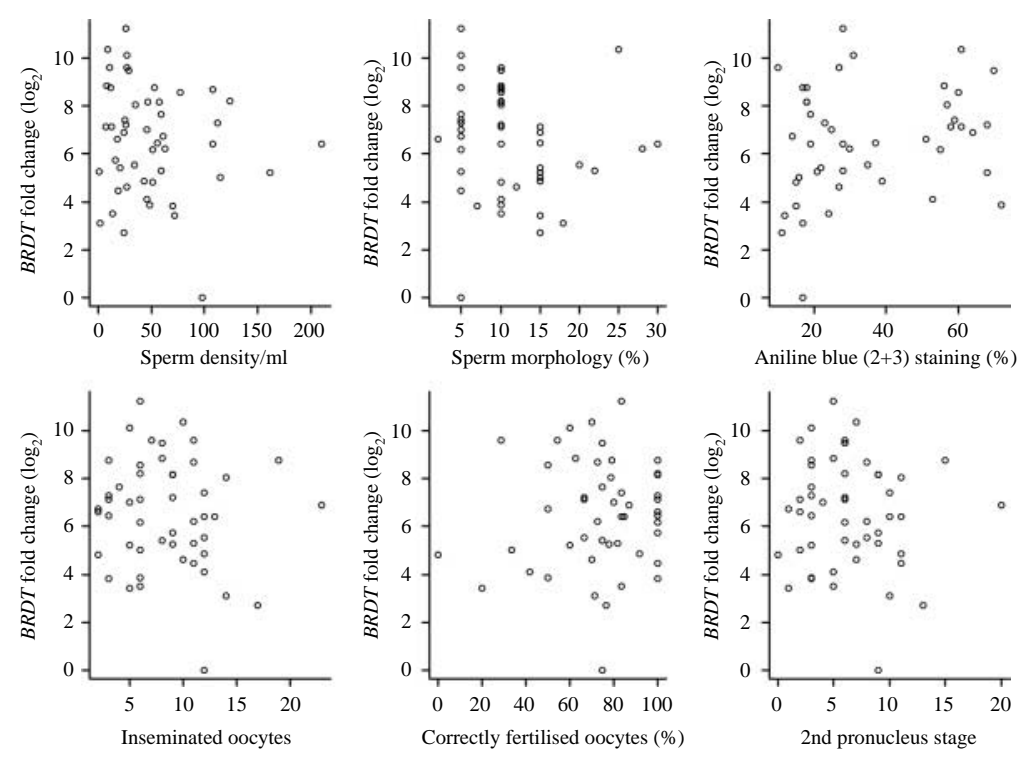

Figure 5 Scatter plot matrix showing correlation between BRDT level and following diagnostic parameters from infertile patients $(n=49)$ : sperm density/ml (Spearman correlation coefficients $r=-0.120, P=0.413)$, sperm morphology $(\%)(r=-0.261, P=0.073)$, aniline blue staining $(2+3)(\%)(r=0.260, P=0.084)$, number of inseminated oocytes $(r=-0.108, P=0.460)$, number of embryos in 2nd pronucleus stage $(r=-0.071$, $P=0.629)$, correctly fertilised oocytes $(r=0.054$, $P=0.714)$

we found 33 gene promoters that were associated with acetylated histone H4K12ac (known as activating mark) and were expressed in four-cell embryos (Zhang et al. 2009). Among them were the following genes: MTMR3, PAX9, MAGEA1, CAMSAP1 and SLC41A2.

In our ChIP experiment, unmodified histone $\mathrm{H} 3$ exhibited a high enrichment in fertile and subfertile men. This may be due to higher amounts of unmodified $\mathrm{H} 3$ than modified $\mathrm{H} 3$. Other possibilities could be a better $\mathrm{H} 3$ antibody affinity and a poor input DNA preparation.

Finally, we were able to demonstrate $B R D T$ mRNAs in sperm of both fertile and subfertile men. A significant difference could be detected between fertile and subfertile men. This is in contrast with data from Wawrzik et al. (2009), who showed similar results for germ cells of oligozoospermic and normozoospermic men. The presence of sperm mRNAs could be explained by the fact that these transcripts are stored for further function in the zygote, as proposed by Miller et al. (2005). However, differential BRDT mRNA levels were observed within the group of fertile donors and subfertile patients suggesting individual variations. Nevertheless, comparing mean values of mRNA level from subfertile and fertile group, we could demonstrate a clear difference between both groups. Owing to high level of variability observed in the $B R D T$ mRNA of donors, we suggest to use larger cohorts of control ejaculates for further experiments in order to establish the normal, physiological range of mRNA levels in spermatozoa.

The fact that spermatozoa contain high levels of $B R D T$ mRNA, and both the promoter and the coding region of the BRDT gene are associated with modified histones representing epigenetic marks that may be transmitted to the oocyte suggests a possible role for BRDT during early embryo development.

\section{Materials and Methods}

\section{Ejaculate samples of fertile donors and subfertile patients}

Ejaculate samples of fertile donors ( $n=5$ for ChIP and $n=6$ for mRNA experiments) were collected at the Department of Urology, Pediatric Urology and Andrology, University of Giessen, Germany. All samples were classified according to WHO criteria (World Health Organization 2010).

Ejaculate samples of subfertile donors $(n=11$ for ChIP and $n=49$ for mRNA experiments) were obtained from patients who underwent ICSI procedure at the IVF Center of Middle Hessia, Germany. Subfertile patients were selected due to teratozoospermia and asthenozoospermia. In addition, aniline blue staining has been performed (Henkel et al. 1994) representing an indicator for defective chromatin condensation during spermiogenesis, as it stains lysine-rich histones, but not arginine or cysteine-rich protamines. In total, $64.3 \%$ of patients and $37.5 \%$ of fertile donors displayed defects in chromatin compaction. All samples for this study were obtained after patients signed written informed consent. Ejaculate and ICSI parameters of fertile and subfertile men are summarised in Tables 1 and 2 .

\section{Chromatin immunoprecipitation}

ChIP assay requires at least $10^{6}$ sperm cells per immunoprecipitation. Owing to low sperm concentration, ejaculate samples from infertile patients were pooled. The first pool consisted of five patients, and the second pool contained sperm samples from six individuals. Formaldehyde cross-linking and ChIP assays of ejaculated sperm were performed, according to the manufacturer's instructions (Chromatin Immunoprecipitation Assay Kit, Millipore, Temecula, CA, USA). DNA was recovered by phenol/chloroform extraction and ethanol precipitation. The size of sonicated DNA was monitored by gel electrophoresis. Sonicated cells were then diluted tenfold in 
Table 1 Ejaculate parameters of fertile donors.

\begin{tabular}{lll}
\hline & $\boldsymbol{n}$ & $\%$ \\
\hline $\begin{array}{l}\text { Ejaculate volume }(\mathrm{ml}) \\
<2\end{array}$ & 0 & \\
$\geq 2$ & 8 & 100 \\
Sperm density (million/ml) & & \\
$\quad<20$ & 0 & 0 \\
$\geq 20$ & 8 & 100 \\
Morphology $(\%)$ & & \\
$<15$ & 3 & 37.5 \\
$\geq 15$ & 5 & 62.5 \\
Motility $(\%)$ & & \\
$<50$ & 1 & 12.5 \\
$\geq 50$ & 7 & 12.5 \\
WHO a $<20$ & 1 & 87.5 \\
WHO a $\geq 20$ & 7 & 75 \\
WHO b $<20$ & 6 & 25 \\
WHO b $\geq 20$ & 2 & 50 \\
WHO c $<10$ & 4 & 12.5 \\
WHO c $\geq 10$ & 4 & 87.5 \\
WHO d $<50$ & 1 & 62.5 \\
WHO d $\geq 50$ & 7 & 37.5 \\
Aniline blue staining (2+3) (\%) & & \\
$<25$ & 5 & \\
$\geq 25$ & 3 & \\
\hline
\end{tabular}

ChIP dilution buffer with protease inhibitors and processed for ChIP. For each condition, 10\% of immunoprecipitation without antibody was saved as total input chromatin. Immunoprecipitations were performed using 2-8 $\mu$ l of polyclonal rabbit anti-IgG (negative control; Abcam, Cambridge, UK), polyclonal rabbit anti-H3 (positive control; Abcam), polyclonal rabbit anti-H3K9ac (Abcam), monoclonal mouse anti-H3K9dm (Abcam), polyclonal anti-H3K9tm (Abcam) and polyclonal rabbit anti-H3K27tm (Millipore, Schwalbach, Germany) antibodies. After the final step, each immunoprecipitation sample was resuspended in $20 \mu \mathrm{l}$ of aqua bidest. For chip array with H4K12ac (Abcam ab1761), purified IP-probe (Qiaquick Purification Kit, Qiagen) and $10 \mathrm{ng}$ of input material (total chromatin) were prepared by adapting the protocol for whole genome amplification using the Sigma GenomePlex WGA kit (Sigma-Aldrich) as described in $\mathrm{O}^{\prime}$ Green et al. (2006). The required amount of DNA for microarray analysis (4 $\mu \mathrm{g} / \mathrm{sample}$ ) was generated using WGA Reamplifikation Kit (Sigma). Amplicons were applied to the HG18 human $5 \mathrm{~kb}$ promoter array from NimbleGen System. Labelling and hybridisation of the probes for ChIP-on-chip analysis was performed by NimbleGen Service ImaGenes $\mathrm{GmbH}$ (Berlin, Germany), for details see Arpanahi et al. (2009). Microarray data are available for download at GEO http://www.ncbi.nlm.nih.gov/geo/, accession numbers GSM 327833 and GSM327832. Data from subfertile patients are not yet published.

\section{Real-time PCR}

For evaluation of ChIP assays, amplification of 105-176 bp products from the genomic BRDT promoter region and exon was applied (Fig. 1). PCR products did not overlap. Primers (MWG, Ebersberg, Germany) are listed in Table 3. We chose three primer pairs for the promoter region, as they represent the most likely binding sites for histone modifications (Arpanahi et al. 2009, Hammoud et al. 2009). Although binding of histones to exon regions seems to have no impact on the transcriptional activity in the embryo, histone binding to the BRDT exon could not completely be excluded. Therefore, we applied one primer pair that specifically amplifies a sequence within the first exon of the BRDT gene in order to investigate, whether there is a possible disorder due to impaired chromatin condensation in the coding region of infertile patients. PCRs contained $2 \mu \mathrm{l}$ of immunoprecipitation sample, $10 \mathrm{pmol} / \mu \mathrm{l}$ of each primer, $12.5 \mu \mathrm{l}$ iQ SYBR Green Supermix (Bio-Rad) in $23 \mu \mathrm{l}$ of total volume. PCR conditions were an initial step of $3 \mathrm{~min}$ at $95^{\circ} \mathrm{C}$, followed by 40 cycles of $30 \mathrm{~s}$ at $95^{\circ} \mathrm{C}, 30 \mathrm{~s}$ at 58-62 ${ }^{\circ} \mathrm{C}$ and $1 \mathrm{~min}$ at $72{ }^{\circ} \mathrm{C}$. After amplification, $10 \mu \mathrm{l}$ of the PCR product was electrophoresed on an $1.5 \%$ agarose gel, and DNA was visualised under u.v. light. Each PCR generated only the expected specific amplicon, as shown by melting temperature profiles of final products and gel electrophoresis. In addition, PCR products were checked by sequencing (Scientific Research and Development $\mathrm{GmbH}$, Oberursel, Germany).

Table 2 Ejaculate and post-fertilisation parameters of patients with subfertility treated by ICSI.

\begin{tabular}{|c|c|c|}
\hline & $n$ & $\%$ \\
\hline \multicolumn{3}{|c|}{ Ejaculate volume $(\mathrm{ml})$} \\
\hline$<2$ & 11 & 18.3 \\
\hline$\geq 2$ & 49 & 81.7 \\
\hline \multicolumn{3}{|c|}{ Sperm density (million/ml) } \\
\hline$<20$ & 19 & 31.7 \\
\hline$\geq 20$ & 41 & 68.3 \\
\hline \multicolumn{3}{|l|}{ Morphology (\%) } \\
\hline$<15$ & 53 & 88.3 \\
\hline$\geq 15$ & 7 & 11.7 \\
\hline \multicolumn{3}{|l|}{ Motility $(\%)$} \\
\hline$<50$ & 43 & 71.7 \\
\hline$\geq 50$ & 17 & 28.3 \\
\hline WHO a $<20$ & 57 & 95.0 \\
\hline WHO a $\geq 20$ & 3 & 5.0 \\
\hline WHO b $<20$ & 47 & 78.3 \\
\hline WHO $b \geq 20$ & 13 & 21.7 \\
\hline WHO c $<10$ & 36 & 60.0 \\
\hline WHO c $\geq 10$ & 24 & 40.0 \\
\hline WHO d $<50$ & 11 & 18.3 \\
\hline WHO d $\geq 50$ & 49 & 81.7 \\
\hline \multicolumn{3}{|c|}{ Aniline blue staining $(2+3)(\%)$} \\
\hline$<25$ & 20 & 35.7 \\
\hline$\geq 25$ & 36 & 64.3 \\
\hline \multicolumn{3}{|c|}{ No. of inseminated oocytes } \\
\hline$<10$ & 39 & 65.0 \\
\hline$\geq 10$ & 21 & 35.0 \\
\hline \multicolumn{3}{|c|}{ No. of embryos in 1st pronucleus stage } \\
\hline$<10$ & 49 & 81.7 \\
\hline$\geq 10$ & 11 & 18.3 \\
\hline \multicolumn{3}{|c|}{ No. of embryos in 2 nd pronucleus stage } \\
\hline$<10$ & 49 & 81.7 \\
\hline$\geq 10$ & 11 & 18.3 \\
\hline \multicolumn{3}{|c|}{ Correctly fertilised oocytes (\%) } \\
\hline$<60$ & 16 & 26.7 \\
\hline $60-90$ & 31 & 51.7 \\
\hline 100 & 13 & 21.7 \\
\hline \multicolumn{3}{|l|}{ Pregnancy } \\
\hline Yes & 33 & 55.0 \\
\hline No & 27 & 45.0 \\
\hline
\end{tabular}


Table 3 Primer pairs used in real-time PCR and standard PCR experiments.

\begin{tabular}{|c|c|c|c|}
\hline Name & Accession number & Primer sequence $5^{\prime}-3^{\prime}$ & Product size $(b p)$ \\
\hline BRDT-pr1-F & NM_001726 & GAG GAA TCA GTG TGG GAT CG & 119 \\
\hline BRDT-pr1-R & NM_001726 & TCA GTA GTG CCC CСA TCT TC & 119 \\
\hline BRDT-pr2-F & NM_001726 & GAA GAT GGG GGC АCT АCT GA & 176 \\
\hline BRDT-pr2-R & NM_001726 & GCG AGA CTG CAT CTC AAA CA & 176 \\
\hline BRDT-pr3-F & NM_001726 & GTG CGT TGC TTT CTT GTG AA & 105 \\
\hline BRDT-pr3-R & NM_001726 & TTT CCT GAA GCG GAA GTC TG & 105 \\
\hline BRDT-ex-F & Jones et al. (1997) & AAT GTC TCT GCC AAG TCG ACA A & 175 \\
\hline BRDT-ex-R & Jones et al. (1997) & AGC ATC CAC AGG ACG TTG AAA G & 175 \\
\hline ACTB-F & NM_001101 & TTC CTT ССT GGG CAT GGA GT & 90 \\
\hline ACTB-R & NM_001101 & TAC AGG TCT TTG CGG ATG TC & 90 \\
\hline HSP90AB1-F & NM_007355 & AAG AGA GCA AGG CAA AGT TTG AG & 120 \\
\hline HSP90AB1-R & NM_007355 & TGG TCA CAA TGC AGC AAG GT & 120 \\
\hline GAPDH-F & NM_002046 & TCT ССТ СТG АСТ TCA ACA GCG AC & 126 \\
\hline GAPDH-R & NM_002046 & CCC TGT TGC TGT AGC CAA ATT C & 126 \\
\hline ATP5B-F & NM_001686 & TCA CCC AGG CTG GTT CAG A & 80 \\
\hline ATP5B-R & NM_001686 & AGT GGC CAG GGT AGG CTG AT & 80 \\
\hline CD45-F & Lamb̄ard et al. (2004) & TGC AGA TGC CTA CCT TAA TGC & 844 \\
\hline CD45-R & Lambard et al. (2004) & CAC ATT GCA GCA CTT CCA TT & 844 \\
\hline KIT-F & Lambard et al. (2004) & AGT ACA TGG ACA TGA AAC CTG G & 780 \\
\hline KIT-R & Lambard et al. (2004) & GAT TCT GCT CAG ACA TCG TCG & 780 \\
\hline
\end{tabular}

Calculations for graphs were processed as follows: $C_{\mathrm{t}}=$ cycle number at which each PCR reaches a predetermined fluorescence threshold. It is set within the loglinear range of all reactions. Enrichment of the immunoprecipitated sample compared with input material was calculated as follows: $\Delta C_{\mathrm{t}}=C_{\mathrm{t}}$ (input) $-C_{\mathrm{t}}$ (immunoprecipitated sample) and $\%$ total $=2^{\Delta C_{\mathrm{t}}} \times 10$ (according to $10 \%$ input chromatin of total immunoprecipitated chromatin) (Frank et al. 2001). For fertile men, PCRs with material of different donors $(n=6)$ were performed. The mean of the $C_{\mathrm{t}}$ values of different donors was calculated. In subfertile men, the ejaculate of five and six donors was pooled to perform ChIP. In this case, the mean of different PCRs with the same material was calculated.

\section{$R N A$ isolation and first-strand $C D N A$ synthesis}

RNA extraction from ejaculates was performed using the RNA extraction kit RNeasy MINI (Qiagen) including a DNase treatment. The purity of extracted RNA was assessed by measuring the optical density at wavelengths of 230, 260 and $280 \mathrm{~nm}$ with Nanodrop Photometer (Eppendorf, Hamburg, Germany). In addition, RNA integrity was analysed on an Agilent 2100 Bioanalyzer (Agilent Technologies, Palo Alto, CA, USA) using the RNA 6000 Nano Assay according to the manufacturer's instructions and the Agilent 2100 Bioanalyzer Software (Fig. 6). The RNA 6000 ladder was purchased from Ambion (Austin, TX, USA).

First-strand cDNA synthesis was performed using Sensiscript (Qiagen). For cDNA synthesis, $2 \mu \mathrm{l} 10 \times$ RT buffer, $2 \mu \mathrm{l}$ dNTP $\operatorname{mix}(5 \mathrm{mM}$ each dNTP), $2 \mu$ l Oligo-dT primer $(10 \mu \mathrm{M}), 1 \mu \mathrm{l}$ (10 IU) RNase inhibitor and $1 \mu$ l Sensiscript reverse transcriptase were added. Samples were incubated at $37^{\circ} \mathrm{C}$ for $60 \mathrm{~min}$.

Furthermore, contaminations with somatic cells or immature germ cells were checked using primer pairs for leukocytes (CD45) and testicular germ cells (KIT (C-KIT); Lambard et al. 2004). We did not detect any contamination in our samples (Fig. 7).

\section{Real-time RT-PCR}

Real-time RT-PCR was performed using iQ SYBR Green Supermix and iCycler (Bio-Rad). Per sample, $25 \mathrm{ng}$ total cDNA of fertile $(n=6)$ and subfertile $(n=49)$ men were used for amplification of heat shock protein (HSP90AB1; previously known as $H S P C B)$, glyceraldehyde-3-phosphate dehydrogenase $(G A P D H), \beta$-actin $(A C T B)$ and ATP-synthase subunit $5 \mathrm{~B}(A T P 5 B)$ as reference genes and $B R D T$ as target gene. For the detection of the BRDT gene, the primer pair for the first exon was used. The PCR efficiency for each single primer pair was determined using serial tenfold dilutions of cDNA transcripts of each gene. All PCR assays yielded specific products of the expected sequence, and the efficiency of all assays was between 95 and 99\%. The linear correlation coefficient $\left(R^{2}\right)$, an indicator of fit for the standard curve (equation: PCR efficiency $\left.=\left(10^{(-1 / \text { slope })}-1\right) \times 100\right)$, plotted to the standard data points of all genes ranged from 0.988 to 1.000. Cycling conditions were $95^{\circ} \mathrm{C}$ for $3 \mathrm{~min}$, followed by 40 cycles of $95^{\circ} \mathrm{C}$ for $30 \mathrm{~s}, 60^{\circ} \mathrm{C}$ for $30 \mathrm{~s}$ and $72{ }^{\circ} \mathrm{C}$ for $30 \mathrm{~s}$. Primer

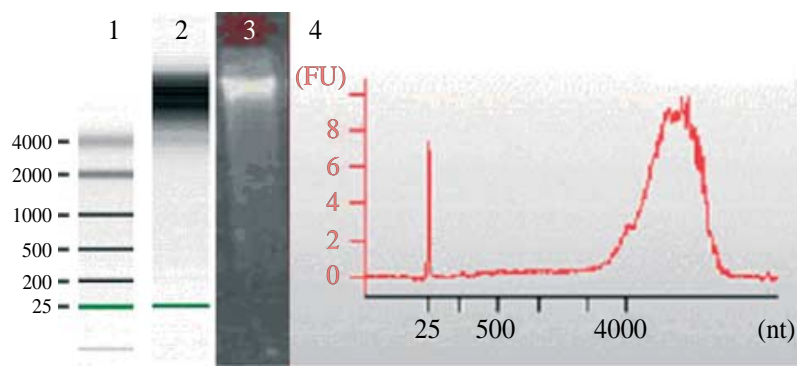

Figure 6 Quality control of sperm RNA using agarose gel electrophoresis (3=RNA) and Agilent 2100 Bioanalyzer (1, RNA 6000 ladder, 2, RNA, 4, electropherogram). High amount of RNA ( $>4000$ nucleotides) is indicative for intact RNA. 18S RNA was absent and $28 \mathrm{~S}$ RNA was reduced in sperm RNA. This was expected as sperm contain no or a reduced amount of rRNA (Ostermeier et al. 2002). 


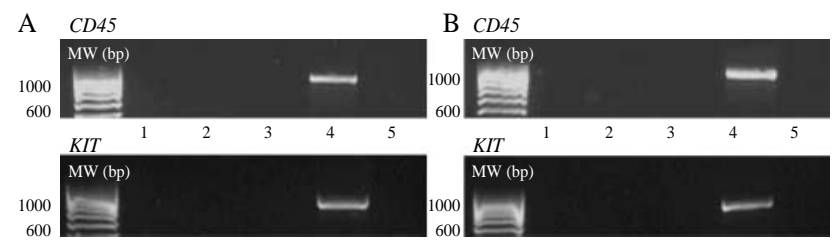

Figure 7 Contamination check of sperm mRNA using CD45 and KIT as markers. Agarose gel showing PCR products of $C D 45$ and KIT in fertile donors (A) and subfertile patients (B). Lanes 1-3 indicate samples free of contamination isolated from ejaculated sperm. Lane 4 shows the PCR product when blood cDNA (CD45) and accordingly testis CDNA (KIT) were used as positive controls. Lane 5 contains Rnase-free water.

pairs are summarised in Table 3. Values recorded for quantification were the fractional cycle numbers $\left(C_{\mathrm{t}}\right)$ where the background-corrected amplification curves crossed a threshold value. Subsequently, candidate reference genes have been selected using GeNorm software (GenEx pro 4.3.7, MultiD Analyses AB, Göteborg, Sweden), as previously described by Vandesompele et al. (2002) and Normfinder software (GenEx pro 4.3.7; Andersen et al. 2004).

Applying GeNorm software, ACTB and GAPDH were determined as best combination of two reference genes $(M$ value $=1.3)$. Normfinder software determined $A C T B$ and HSP9OAB1 as the most stable reference genes with lowest variability examined (variability of the genes: 0.6). For further real-time RT-PCR data analysis, we combined GAPDH and $A C T B$ as reference genes. Relative expression levels were calculated using the GenEx pro 4.3.7 software.

\section{Statistical analysis}

The statistical analysis was performed using SAS V9.2 (SAS Institute, Cary, NC, USA). As normal distribution could be assumed for the parameter BRDT fold change, comparing the two groups healthy donors $(n=6)$ and subfertile patients $(n=49)$, $t$-test could be applied. However, normal distribution could not be assumed for other parameters of interest (ejaculate parameters from subfertile patients and healthy donors). Therefore, Spearman correlation coefficients were calculated for the evaluation of possible associations between BRDT level and diagnostic parameters. These analyses were done in explorative sense, which means the computed $P$ values are only a measure for the reproducibility of the observed results, under the null hypothesis there is no association between BRDT fold change and the diagnostic parameter of interest.

\section{Declaration of interest}

The authors declare that they have no direct or indirect commercial or financial incentive associated with publishing this manuscript.

\section{Funding}

This work was supported by the Bayer Vital $\mathrm{GmbH}$ and the German Society of Andrology (grant: Bonn - Bad Godesberg, 01.12.07).

\section{Acknowledgements}

We thank Barbara Fröhlich, Kerstin Wilhelm and Angela Erkel, Department of Urology, Pediatric Urology and Andrology, Justus Liebig University of Giessen, for technical assistance, as well as Christine Scheibelhut, Institute for Medical Informatics, Justus Liebig University of Giessen, for discussion regarding statistical analysis.

\section{References}

Allfrey VG, Faulkner R \& Mirsky AE 1964 Acetylation and methylation of histones and their possible role in the regulation of RNA synthesis. PNAS 51 786-794.

Andersen CL, Jensen JL \& Orntoft TF 2004 Normalization of real time quantitative reverse transcription PCR data: a model-based variance estimation approach to identify genes suited for normalization, applied to bladder and colon cancer data sets. Cancer Research 64 5245-5250.

Arpanahi A, Brinkworth M, Iles D, Krawetz SA, Paradowska A, Platts AE, Saida M, Steger K, Tedder P \& Miller D 2009 Endonuclease-sensitive regions of human spermatozoal chromatin are highly enriched in promoter and CTCF binding sequences. Genome Research 19 1338-1349.

Azuara V, Perry P, Sauer S, Spivakov M, Jørgensen HF, John RM, Gouti M, Casanova M, Warnes G, Merkenschlager M et al. 2006 Chromatin signatures of pluripotent cell lines. Nature Cell Biology 8 532-538.

Bernstein BE, Kamal M, Lindblad-Tho K, Bekiranov S, Bailey DK, Huebert DJ, McMahon S, Karlsson EK, Kulbokas EJ III, Gingeras TR et al. 2005 Genomic maps and comparative analysis of histone modifications in human and mouse. Cell 120 169-181.

Bernstein BE, Mikkelsen TS, Xie X, Kamal M, Huebert DJ, Cuff J, Fry B, Meissner A, Wernig M, Plath K et al. 2006 A bivalent chromatin structure marks key development genes in embryonic stem cells. Cell $\mathbf{1 2 5}$ 233-236.

Bernstein BE, Meissner A \& Lander ES 2007 The mammalian epigenome. Cell 128 669-681.

Dobson AT, Raja R, Abeyta MJ, Taylor T, Shen S, Haqq C \& Pera RA 2004 The unique transcriptome through day 3 of human preimplantation development. Human Molecular Genetics 13 1461-1470.

Frank SR, Schroeder M, Fernandez P, Taubert S \& Amati B 2001 Binding of c-Myc to chromatin mediates mitogen-induced acetylation of histone $\mathrm{H} 4$ and gene activation. Genes and Development 15 2069-2082.

Gardiner-Garden M, Ballesteros M, Gordon M \& Tam PPL 1998 Histoneand protamine-DNA association: conservation of different patterns within the $\beta$-globin domain in human sperm. Molecular and Cellular Biology 18 3350-3356.

Gatewood JM, Cook GR, Balhorn R, Bradbury EM \& Schmid CW 1987 Sequence-specific packaging of DNA in human sperm chromatin. Science 236 962-964.

Hammoud SS, Nix DA, Zhang H, Purwar J, Carrell DT \& Cairns BR 2009 Distinctive chromatin in human sperm packages genes for embryo development. Nature $\mathbf{4 6 0} 473-478$.

Haynes SR, Dollard C, Winston F, Beck S, Trowsdale J \& David IB 1992 The bromodomain: a conserved sequence found in human, Drosophila and yeast proteins. Nucleic Acids Research 202603.

Hecht N, Behr R, Hild A, Bergmann M, Weidner W \& Steger K 2009 The common marmoset (Callithrix jacchus) as a model for histone and protamine expression during human spermatogenesis. Human Reproduction 24 536-545.

Henkel RR, Franken DR, Lombard CJ \& Schill WB 1994 Selective capacity of glass-wool filtration for the separation of human spermatozoa with condensed chromatin: a possible therapeutic modality for male-factor cases? Journal of Assisted Reproduction and Genetics 11 395-400.

Jones MH, Numata M \& Shimane M 1997 Identification and characterisation of BRDT: a testis-specific gene related to bromodomain genes RING3 and Drosophila fsh. Genomics 45 529-534.

Lalancette C, Miller D, Li Y \& Krawetz SA 2008 Paternal contributions: new functional insights for spermatozoal RNA. Journal of Cellular Biochemistry 104 1570-1579. 
Lambard S, Galeraud-Denis I, Martin G, Levy R, Chocat A \& Carreau S 2004 Analysis and significance of mRNA in human ejaculated sperm from normozoospermic donors: relationship to sperm motility and capacitation. Molecular Human Reproduction 10 535-541.

Li B, Carey M \& Workman JL 2007 The role of chromatin during transcription. Cell 128 707-719.

Miller D, Ostermeier C \& Krawetz SA 2005 The controversy, potential and roles of spermatozoal RNA. Trends in Molecular Medicine 11 156-163.

Morinière J, Rousseaux S, Steuerwald U, Soler-López M, Curtet S, Vitte AL, Govin J, Gaucher J, Sadoul K, Hart DJ et al. 2009 Cooperative binding of two acetylation marks on a histone tail by a single bromodomain. Nature 461 664-668.

O'Green H, Nicolet CM, Blahnik K, Green R \& Farnham PJ 2006 Comparison of sample preparation methods for ChIP-chip assays. BioTechniques 41 557-580.

Ostermeier GC, Dix DJ, Miller D, Khatri P \& Krawetz SA 2002 Spermatozoal RNA profiles of normal fertile men. Lancet 360 $772-777$.

Ostermeier GC, Miller D, Huntriss JD, Diamond MP \& Krawetz SA 2004 Reproductive biology: delivering spermatozoan RNA to the oocyte. Nature 429154.

Pivot-Pajot C, Caron C, Govin J, Vion A, Rousseaux S \& Khochbin S 2003 Acetylation-dependent chromatin reorganization by BRDT, a testisspecific bromodomain-containing protein. Molecular and Cellular Biology 23 5354-5365.

Rassoulzadegan M, Grandjean V, Gounon P, Vincent S, Gillot I \& Cuzin F 2006 RNA mediated non-Mendelian inheritance of an epigenetic change in the mouse. Nature 441 469-474.

Rousseaux S, Reynoird N, Escoffier E, Thevenon J, Caron C \& Khochbin S 2008 Epigenetic reprogramming of the male genome during gametogenesis and in the zygote. Reproductive Biomedicine Online $\mathbf{1 6}$ 492-503.

Santos-Rosa H, Schneider R, Bannister AJ, Sherriff J, Bernstein BE, Emre NC, Schreiber SL, Mellor J \& Kouzarides T 2002 Active genes are tri-methylated at K4 of histone H3. Nature $\mathbf{4 1 9} 407-411$.

Schreiber SL \& Bernstein BE 2002 Signaling network model of chromatin. Cell 111 771-778.

Shang E, Salzar G, Crowley TE, Wang X, Lopez RA, Wang X \& Wolgemuth DJ 2004 Identification of unique, differentiation stagespecific patterns of expression of bromodomain-containing genes BRD2, BRD3, BRD4 and BRDT in the mouse testis. Gene Expression Patterns 4 513-519.

Shang E, Nickerson HD, Wen D, Wang X \& Wolgemuth DJ 2007 The first bromodomain of BRDT, a testis specific member of the BET sub-family of double-bromodomain-containing proteins, is essential for male germ cell differentiation. Development 134 3507-3515.

Steger K, Klonisch T, Gavenis K, Drabent B, Doenecke D \& Bergmann M 1998 Expression of mRNA and protein of nucleoproteins during human spermiogenesis. Molecular Human Reproduction 4 939-945.
Strahl BD \& Allis CD 2000 The language of covalent histone modifications. Nature $\mathbf{4 0 3} 41-45$.

Swann K, Saunders CM, Rogers NT \& Lai FA 2006 PLCzeta (zeta): a sperm protein that triggers $\mathrm{Ca}^{2+}$ oscillations and egg activation in mammals. Seminars in Cell \& Developmental Biology 17 264-273.

Tanphaichitr N, Sohbon P, Taluppeth N \& Chalermisarachai P 1978 Basic nuclear proteins in testicular cells and ejaculated spermatozoa in man. Experimental Cell Research 117 347-350.

Turner BM 2000 Histone acetylation and an epigenetic code. BioEssays 22 836-845.

Vakoc CR, Mandat SA, Olenchock BA \& Blobel GA 2005 Histone H3 lysine methylation and HP1 gamma are associated with transcription elongation through mammalian chromatin. Molecular Cell 19 381-391.

Vandesompele J, De Preter K, Pattyn F, Poppe B, Van Roy N, De Paepe A \& Speleman F 2002 Accurate normalization of real time quantitative RT-PCR data by geometric averaging of multiple internal control genes. Genome Biology 3 RESEARCH0034.

Wade PA, Pruss D \& Wolffe AP 1997 Histone acetylation: chromatin in action. Trends in Biochemical Sciences 22 128-132.

Wang Z, Zang C, Rosenfeld JA, Schones DE, Barski A, Cuddapah S, Cui K, Roh TY, Peng W, Zhang MQ et al. 2008 Combinatorial patterns of histone acetylations and methylations in the human genome. Nature Genetics $\mathbf{4 0}$ 897-903.

Wawrzik M, Spiess AN, Herrmann R, Buiting K \& Horsthemke B 2009 Expression of SNURF-SNRPN upstream transcripts and epigenetic regulatory genes during human spermatogenesis. European Journal of Human Genetics 17 1463-1470.

World Health Organization (Ed.) 2010 WHO laboratory manual for the examination and processing of human semen. In WHO Laboratory Manual, 5th edn. Geneva: World Health Organization.

Wykes SM \& Krawetz SA 2003 The structural organization of sperm chromatin. Journal of Biological Chemistry 278 29471-29477.

Zao YX, Li OL, Wang ZX, Wang YF, Wang LY \& Qiao ZD 2006 Characterization of the mRNA profile in ejaculated spermatozoa from healthy fertile men. Zhonghua Nan Ke Xue 12 900-903.

Zhang P, Zucchelli M, Bruce S, Hambiliki F, Stavreus-Evers A, Levkov L, Skottman H, Kerkelä E, Kere J \& Hovatta O 2009 Transcriptome profiling of human pre-implantation development. PLoS ONE 4 e7844.

Zheng Y, Yuan W, Zhou Z, Xu M \& Sha JH 2005 Molecular cloning and expression of a novel alternative splicing variant of BRDT gene. International Journal of Molecular Medicine 15 315-332.

Received 15 March 2010

First decision 12 April 2010

Revised manuscript received 25 May 2010

Accepted 10 June 2010 